\title{
Article \\ Unraveling the Metabolite Signature of Endophytic Bacillus velezensis Strain Showing Defense Response towards Fusarium oxysporum
}

\author{
Yang Cao ${ }^{1,2}$, Wei Ding ${ }^{1, *}$ and Chang Liu ${ }^{3}$ \\ 1 College of Agriculture, Northeast Agricultural University, Harbin 150000, China; Caoyang19840523@163.com \\ 2 Experimental Centre, Heilongjiang Agricultural Economy Vocational College, Mudanjiang 157000, China \\ 3 Mudanjiang Branch, Heilongjiang Academy of Agricultural Sciences, Mudanjiang 157000, China; \\ changchang_3000@163.com \\ * Correspondence: dingwei@neau.edu.cn; Tel.: +86-451-55191067
}

Citation: Cao, Y.; Ding, W.; Liu, C. Unraveling the Metabolite Signature of Endophytic Bacillus velezensis Strain Showing Defense Response towards Fusarium oxysporum. Agronomy 2021, 11, 683. https:// doi.org/10.3390/agronomy11040683

Academic Editor: Mukesh Dubey

Received: 18 February 2021

Accepted: 1 April 2021

Published: 2 April 2021

Publisher's Note: MDPI stays neutral with regard to jurisdictional claims in published maps and institutional affiliations.

Copyright: (c) 2021 by the authors. Licensee MDPI, Basel, Switzerland. This article is an open access article distributed under the terms and conditions of the Creative Commons Attribution (CC BY) license (https:// creativecommons.org/licenses/by/ $4.0 /)$.

\begin{abstract}
Seedling blight, caused by the fungus Fusarium oxysporum, significantly lowers rice production globally. Earlier reports have opined that endophytic bacteria strains could be possible biocontrol agents, but the mechanistic actions involved are still unclear. Therefore, this study aimed to isolate the endophytic bacteria with high inhibitory activity and elucidate its possible mechanisms for inducing resistance by metabolomics. The results showed that mdj-36 had the strongest in vitro pathogen inhibition of F. oxysporum, while mdj-34 displayed the lowest inhibitory activity identified as Bacillus velezensis strains. Metabolomic analyses demonstrated that $B$. velezensis mdj-36 growth medium could produce higher organic acids, terpenes, and diterpene than $B$. velezensis mdj-34. Further investigation revealed that 'secondary bile acid biosynthesis' and 'glycerophospholipid metabolism' pathways played essential roles in defense response towards F. oxysporum. This study's findings provide a credible theoretical basis for the possible use of the $B$. velezensis strain against rice seedling blight.
\end{abstract}

Keywords: rice; seedling blight; metabolome; organic acid; terpenes; diterpene

\section{Introduction}

As an essential global staple crop, rice (Oryza sativa L.) provides a stable food supply for over four billion people, with the Asian region regarding it as a vital energy source and diet composition [1]. As the world's population soars, so has demand for rice, but several economic diseases have constrained its increased and sustained production. The rice seedling blight is one of the most destructive fungal diseases prevalent at the seedlings-bed level. As a biotic factor, seedling blight infection can lower agricultural productivity [2]. Rice seedling blight management is complex because of the plant's high susceptibility levels to the disease. Conventionally, its control uses fungicides such as imazalil, tolclofos-methyl, fenaminosulf, liturium, and hymexazol [3,4], but concerns have been raised over their negative environmental impacts and their effects on humans. These have informed research efforts towards developing alternative techniques to control the disease effectively [5].

The use of biological control agents as an effective alternative to fungicides is gaining attention in modern agricultural research. Endophytic bacteria have been identified as promising biocontrol agents as they can grow in plants with minimal adverse effects [3] and produce natural substances, which can ameliorate disease severity in plants [6,7]. Compared with rhizosphere and soil microorganisms, endophytic bacteria can grow much more favorably in plants. They do not have survival competition with soil bacteria and are less affected by field operation and variations in climate parameters [8]. Some recent research efforts have been concerted towards screening potential endophytic Bacillus strains that possess commendable disease-suppressing properties (minimal growth needs, rapid root colonization, and defense protein induction) in view of their application as bioagents [9]. 
Bacteria strains belonging to the Bacillus genera are the most predominant endophytic microorganisms found in plants $[10,11]$, and this is suggestive of their possible role as bioagents against economic pathogens. B. subtilis was found to be antagonistic towards Xanthomonas oryza pv. oryzae inciting bacterial leaf blight disease in rice [12]. It has also been reported that $B$. subtilis can also control sheath blight of rice caused by Rhizoctonia solani Kuhn [13]. Microbes associated with the onset and spread of this economic disease have been reported to belong to the Fusarium genus, Rhizoctonia genus, and Cochliobolus genus [14]. The Fusarium genus has been implicated as the primary causative agent of seedling blight in China, where rice consumption is daily [2]. Thus, the F. oxysporum pathogen is traditionally used to screen endophytic bacteria with antagonism. Based on these antecedents, the present study sets out to isolate, screen, and evaluate potentially effective endophytic bacterial strains to manage seedling blight and unravel the underlying defense response mechanisms towards F. oxysporum through metabolomics. These findings could support the theory and application for the use of endophytic bacteria as biocontrol agents.

\section{Materials and Methods}

\subsection{Pathogens and Plant Samples}

The highly-pathogenic F. oxysporum FO2016038 (Institute of Rice, Northeast Agricultural University, China) was the standard pathogen used in this study. It was maintained on potato dextrose agar (PDA) (potato $200 \mathrm{~g}$, glucose $20 \mathrm{~g}$, agar $20 \mathrm{~g}$, sterile water to $1000 \mathrm{~mL}, \mathrm{pH}$ neutral) medium at $4^{\circ} \mathrm{C}$. Plant samples of rice were collected from an open field (Mudanjiang, Heilongjiang Province, China, $44^{\circ} 44^{\prime} \mathrm{N}, 129^{\circ} 50^{\prime} \mathrm{E}$ ).

\subsection{Isolation of Bacteria from Rice}

The isolation of endophytic bacteria in rice was performed as previously reported [15]. Samples were first cleaned with sterile water, and tissue surfaces were disinfected with $75 \%$ ethanol and $2.5 \%$ sodium hypochlorite for 1 and $4 \mathrm{~min}$, respectively. After soaking in $70 \%$ ethanol for $30 \mathrm{~s}$ and washing with sterile water five times, a measured $0.1 \mathrm{~mL}$ aliquot from the final buffer wash was removed and transferred to $9.9 \mathrm{~mL}$ Luria-Bertani (LB) broth broth to serve as a sterile control. The tissues were drained off with a sterile filter paper, then cut into cubes using sterile scissors and ground in a sterile mortar with $10 \mathrm{~mL}$ of sterile distilled water for $10 \mathrm{~min}$. The obtained solution was then serially diluted and plated on tryptic soy agar (TSA). Finally, colonies were transferred to fresh TSA plates to obtain pure isolates.

\subsection{Screening for Antagonistic Bacterial Strains In Vitro}

As previously described, the bacterial isolates' inhibitory effects against $F$. oxysporum were evaluated by placing a 5-mm diameter mycelial disc of the test pathogen in the center, and bacterial isolates were spot inoculated $3-\mathrm{cm}$ distance from the disc on a PDA [16]. As a control (CK), only the plate was inoculated with F. oxysporum. After five days of incubation at $28{ }^{\circ} \mathrm{C}$, the inhibition rates were calculated as follows:

$$
\text { Inhibition rate }(\%)=1-\frac{\text { the diameter of the treated zone of inhibition }}{\text { the diameter of the control zone of inhibition }} \times 100 \%
$$

\subsection{Molecular Identification of Antagonistic Bacterial Strains}

Selected antagonistic bacterial strains were identified by $16 S$ rRNA gene analysis. The total DNA was extracted from the culture medium $(1 \mathrm{~mL})$ of different isolated strains, and the quality of the genomic DNA was measured using gel monitoring apparatus. The genomic DNA was amplified by using 27 F (5'-AGAGTTTGATCCTGGCTCAG-3') and 1495 R (5'-CTACGGCTACCTTGTTACGA-3') [17]. The results were sequenced by BGI Company (Beijing, China) and screened using the BLAST program (https:/ /blast.ncbi.nlm. nih.gov/Blast.cgi accessed on 2 April 2021). A phylogenetic tree was then constructed via the neighbor-joining method using the software of Mega 6.0. 


\subsection{Application Effect of Endophytic Bacteria on Rice}

\subsubsection{Preparation of Conidial Suspension of Fusarium Oxysporum}

Fusarium oxysporum was prepared on a PDA plate medium and incubated at $25{ }^{\circ} \mathrm{C}$ for seven days. Then, $5 \mathrm{~mL}$ of sterile water was added to the PDA plate medium, and the colony surface was coated lightly with a sterile coating device to obtain a conidia suspension. Subsequently, 2-4 layers of sterile mirror cleaning paper were used to filter the conidia suspension and remove the mycelia or fungus blocks, and a conidia suspension with a concentration of $1 \times 10^{5} / \mathrm{mL}$ was then prepared after microscopic examination of its concentration.

\subsubsection{Preparation of Fermentation Broth of Endophytic Strain mdj-36}

The mdj-36 strain stored at $-80^{\circ} \mathrm{C}$ was inoculated on $\mathrm{LB}$ medium plates to activate the culture. Bacterial colonies of the mdj-36 strain were grown in LB broth at $28^{\circ} \mathrm{C}$ and incubated with $180 \mathrm{rpm}$, and then they were subjected to oscillatory culture to obtain the strain seed solution. Finally, this was added to the fermentation medium at an inoculation amount of $5 \%$, and the strain was incubated at $28{ }^{\circ} \mathrm{C}$ for $20 \mathrm{~h}$.

\subsubsection{Rice Seedling Bed Resistance Test}

The rice seeds were soaked at $25{ }^{\circ} \mathrm{C}$ for two days, and the seeds were seeded in a $7 \mathrm{~cm}$ $\times 7 \mathrm{~cm} \times 6 \mathrm{~cm}$ hole plate, with 20 seeds in each hole. This study tested four treatments; when the rice was grown to the second leaf, it was sprayed with mdj-36 fermentation broth $\left(1 \times 10^{8} \mathrm{CFU} / \mathrm{mL}\right)$, hymexazol $(100 \mathrm{mg} / \mathrm{L})$, thiophanate-methyl $(100 \mathrm{mg} / \mathrm{L})$, and control (water). After $24 \mathrm{~h}$, the conidial suspension of F. oxysporum at a concentration of $1 \times 10^{5} \mathrm{CFU} / \mathrm{mL}$ was inoculated on the rice leaves. The four treated rice seedlings were grown at room temperature. Three holes were selected randomly from each repeat, and the incidence and control effect was investigated after ten days. The incidence and control efficiencies were calculated as follows:

$$
\begin{gathered}
\text { Incidence }(\%)=\frac{\text { number of diseased plants }}{\text { total number of investigated plants }} \times 100 \% \\
\text { Control efficiency }(\%)=1-\frac{\text { treatment incidence }}{\text { control incidence }} \times 100 \%
\end{gathered}
$$

\subsection{Metabolome Analysis}

\subsubsection{Sample Preparation and Metabolites Extraction}

The mdj-36 and mdj-34 strains were singly cultured in $100 \mathrm{~mL}$ of sterile LB broth and fermented at $180 \mathrm{rpm}$ and $28^{\circ} \mathrm{C}$ for $48 \mathrm{~h}$, respectively. The cells were then obtained by centrifugation ( $8000 \mathrm{rpm}, 4{ }^{\circ} \mathrm{C}, 20 \mathrm{~min}$ ), and $50 \mathrm{~mL}$ of each supernatant was filtered using size $0.22-\mu \mathrm{m}$ Millipore filters for storage in liquid nitrogen. These samples were then transported to the Tianjin Novogene Metabolomics Platform for metabolomics analyses. After thawing at $4{ }^{\circ} \mathrm{C}$ and homogenization, some supernatant $(200 \mu \mathrm{L})$ was diluted to the final concentration containing 53\% methanol by Liquid Chromatography Mass Spectrometry (LC-MS)grade water. The samples were subsequently transferred to a fresh Eppendorf tube and centrifuged at $15,000 \times g$ and $4{ }^{\circ} \mathrm{C}$ for $10 \mathrm{~min}$. Next, a $0.22-\mu \mathrm{m}$ membrane was used to filter the supernatants and injected into the LC-MS/MS system for analysis [18,19].

\subsubsection{UHPLC-MS/MS Analysis}

Ultra-High Performance Liquid Chromatography-Mass Spectrometry/Mass Spectrometry (UHPLC-MS/MS)analyses were performed using a Vanquish UHPLC system (Thermo Fisher, Germany) coupled with an Orbitrap Q ExactiveTM HF mass spectrometer (Thermo Fisher, Germany). Samples were injected onto a Hypesil Gold column $(100 \times$ $2.1 \mathrm{~mm}, 1.9 \mu \mathrm{m}$ ) using a $17 \mathrm{~min}$ linear gradient at a flow rate of $0.2 \mathrm{~mL} / \mathrm{min}$. The eluents for the positive polarity mode were eluent $\mathrm{A}(0.1 \% \mathrm{FA}$ in water) and eluent $\mathrm{B}$ (methanol). The eluents for the negative polarity mode were eluent $\mathrm{A}(5 \mathrm{mM}$ ammonium acetate, $\mathrm{pH}$ 9.0) 
and eluent $\mathrm{B}$ (methanol). The solvent gradient was set as follows: $2 \% \mathrm{~B}, 1.5 \mathrm{~min} ; 2-100 \%$ B, $12.0 \mathrm{~min} ; 100 \%$ B, $14.0 \mathrm{~min} ; 100-2 \%$ B, $14.1 \mathrm{~min} ; 2 \%$ B, $17 \mathrm{~min}$. Q ExactiveTM HF mass spectrometer was operated in positive/negative polarity mode with a spray voltage of $3.2 \mathrm{kV}$, capillary temperature of $320^{\circ} \mathrm{C}$, sheath gas flow rate of $40 \mathrm{arb}$, and auxillary gas flow rate of $10 \mathrm{arb}$ [20].

\subsubsection{Data Processing and Metabolite Identification}

The raw data files generated by UHPLC-MS/MS were processed using the Compound Discoverer 3.1 (CD3.1, Thermo Fisher, Waltham, USA) to perform peak alignment, peak picking, and quantitation for each metabolite. The main parameters were set as follows: retention time tolerance, $0.2 \mathrm{~min}$; actual mass tolerance, $5 \mathrm{ppm}$; signal intensity tolerance, 30\%; signal/noise ratio, 3; and minimum intensity, 100,000. After that, peak intensities were normalized to the total spectral intensity. We used the normalized data to predict the molecular formula based on additive ions, molecular ion peaks, and fragment ions. Peaks were matched with the mzCloud, mzVault, and MassList databases to obtain accurate qualitative and relative quantitative results. Statistical analyses were performed using the statistical software R (R version R-3.4.3) and Python (Python 2.7.6 version). When data were not normally distributed, normal transformations were attempted using the area normalization method.

\subsubsection{Data Analysis}

These metabolites were annotated using the Kyoto Encyclopedia of Genes and Genomes (KEGG) database (https: / / www.genome.jp / kegg/pathway.html), HMDB database (https: / / hmdb.ca/metabolites) and LIPID Maps database (http:/ / www.lipidmaps.org/). Principal components analysis (PCA) and partial least squares discriminant analysis (PLSDA) was performed at metaX (a flexible and comprehensive software for processing metabolomics data). We applied univariate analysis ( $t$-test) to calculate the statistical significance ( $p$-value). The metabolites with VIP $>1$ and $p$-value $<0.05$ and fold change $\geq 2$ or Fold Change $(\mathrm{FC}) \leq 0.5$ were considered to be differential metabolites. Volcano plots were used to filter interest-based metabolites on $\log 2$ (fold-change) and -log10p-value of metabolites.

The Pheatmap package plotted the data of differential metabolites in $\mathrm{R}$ language to create a cluster heat map. The functions of these metabolites and metabolic pathways were studied using the KEGG database. The metabolic pathways enrichment of differential metabolites was performed when the ratio was satisfied by $\mathrm{x} / \mathrm{n}>\mathrm{y} / \mathrm{N}$, and the metabolic pathway was considered enrichment when the $p$-value of metabolic pathway $<0.05$. At this level, the metabolic pathway was considered statistically significant enrichment.

\subsection{Statistical Analysis}

Data obtained from this research were from at least three independent assays, and the values reported were expressed as mean \pm standard deviation (SD). Statistically, we used the one-way ANOVA method to compare datasets, followed by Duncan's multiple range test. This study measured statistical differences at $p<0.05$.

\section{Results}

\subsection{Antifungal Activity}

All endophytic bacteria were isolated from the rice samples. A total of 10 strains were preliminarily identified as Bacillus strains using morphological characteristics techniques. They all showed inhibitory activity against F. oxysporum FO2016038 in dual culture bioassay (Table 1). The maximum inhibition rate was found in mdj-36, as revealed from more than $50 \%$ mycelial inhibition. The inhibition rate in mdj-34 was significantly lower $(p<0.05)$ than other strains. Therefore, these two isolates were selected to ascertain the antagonistic mechanism against F. oxysporum further. 
Table 1. Inhibition rate of F. oxysporum FO2016038 by bacteria isolated from rice samples.

\begin{tabular}{cc}
\hline Strain & Inhibition Rate (\%) \\
\hline mdj-1 & $49.17 \pm 2.02^{\mathrm{b}}$ \\
mdj-3 & $43.83 \pm 1.49^{\mathrm{c}}$ \\
mdj-5 & $45.39 \pm 2.15^{\mathrm{b}, \mathrm{c}}$ \\
mdj-10 & $36.11 \pm 1.97^{\mathrm{d}}$ \\
mdj-18 & $30.01 \pm 2.03^{\mathrm{e}}$ \\
mdj-27 & $41.95 \pm 3.53^{\mathrm{c}}$ \\
mdj-30 & $46.40 \pm 3.50^{\mathrm{b}, \mathrm{c}}$ \\
mdj-34 & $26.46 \pm 1.76^{\mathrm{f}}$ \\
mdj-36 & $56.67 \pm 3.06^{\mathrm{a}}$ \\
CK-37 & $43.80 \pm 2.50^{\mathrm{c}}$ \\
\hline
\end{tabular}

All values were expressed as mean \pm SD. Varying significant differences were noticed between tested strains $(p<0.05)$.

\subsection{Isolation and Identification of Antagonistic Bacteria}

To gain further insights into the underlying mechanism of different antagonistic activity, mdj-36 and mdj-34 were identified by $16 \mathrm{~S}$ rRNA gene analysis. We then constructed a phylogenetic tree based on these results using the neighboring method. The results demonstrated that the two isolates belonged to the Bacillus velezensis strain (Figure 1).

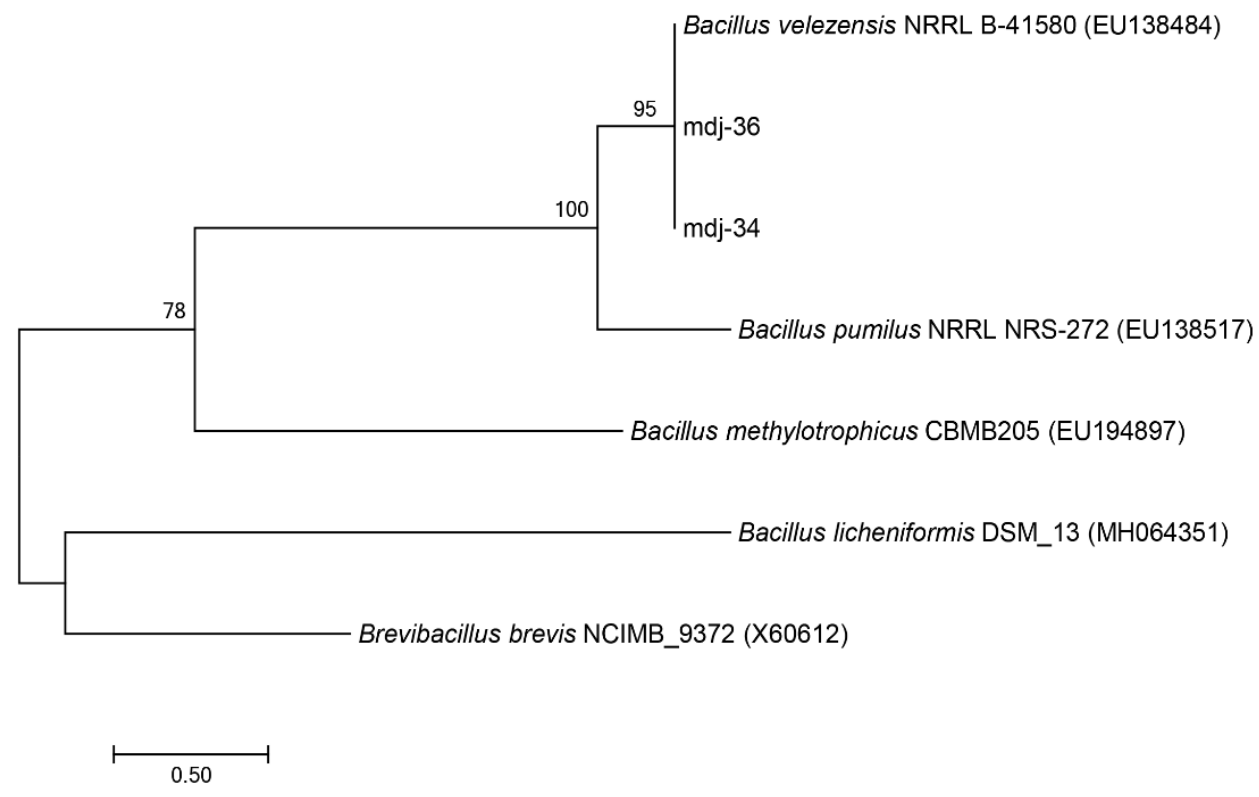

Figure 1. The phylogenetic tree based on DNA sequences encoding $16 \mathrm{~S}$ rRNA gene for the two selected strains. Bootstrap values (\%) presented at the branches were calculated from 1000 replications.

\subsection{Control Effect of Endophytic Bacteria on Rice Seedling Blight}

Seedling bed efficacy assessments showed that the incidence of $B$. velezensis mdj-36 treatment was significantly lower $(p<0.05)$ than that of the hymexazol, thiophanate-methyl, and control groups (Figure 2A). Also, B. velezensis mdj-36 treatment had the highest control efficiency of $73.57 \pm 6.11 \%$, which were significantly higher than that of hymexazol and thiophanate-methyl (Figure 2B). The above data implied that $B$. velezensis mdj-36 strain could be used as a biocontrol agent for rice seedling blight. 

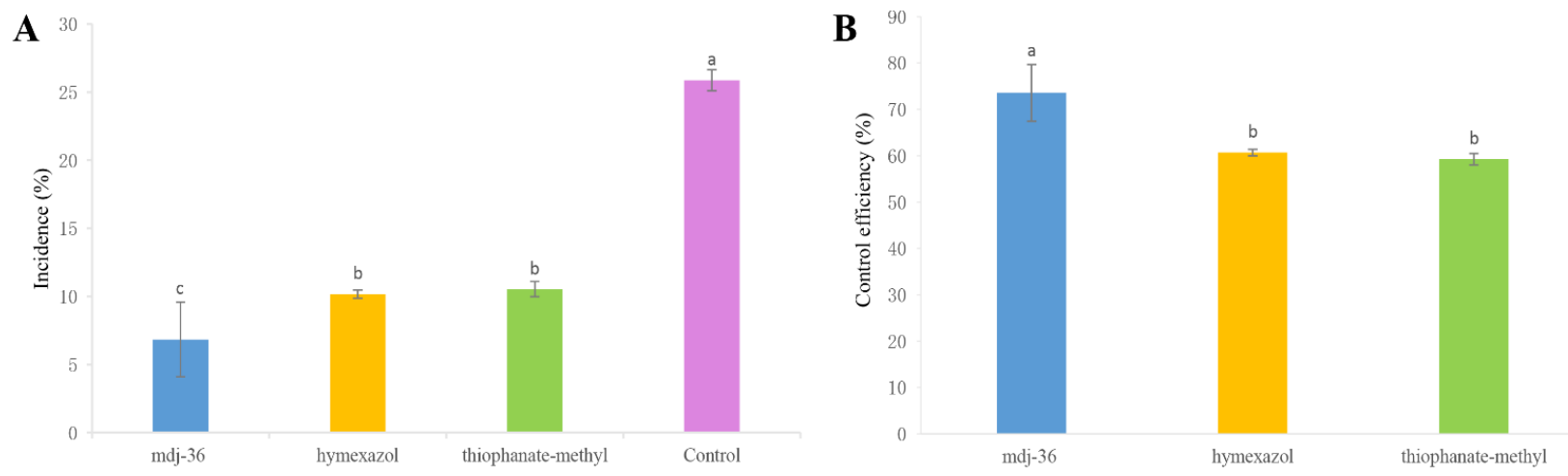

Figure 2. Efficacy evaluation of antagonistic B. velezensis mdj-36 against Fusarium oxysporum-induced rice seedling blight for ten days. (A) incidence, and (B) control efficiency. All values were expressed as mean $\pm \mathrm{SD}$. Varying significant differences were noticed between tested strains $(p<0.05)$.

\subsection{Metabolomics Characteristics of All Samples}

Principal-component analysis (PCA) and partial least squares discriminant analysis (PLS-DA) of the 12 analyzed samples' metabolomics profiles were conducted to provide information on the differences between $B$. velezensis mdj-36 and mdj-34 growth media. As shown in Figure 3, PCA analysis of metabolites determined through LC-MS (+) and LC-MS (-) found significant differences in mdj-36 and mdj-34 growth media's metabolic compositions. This observation was consistent with the PLS-DA analysis.
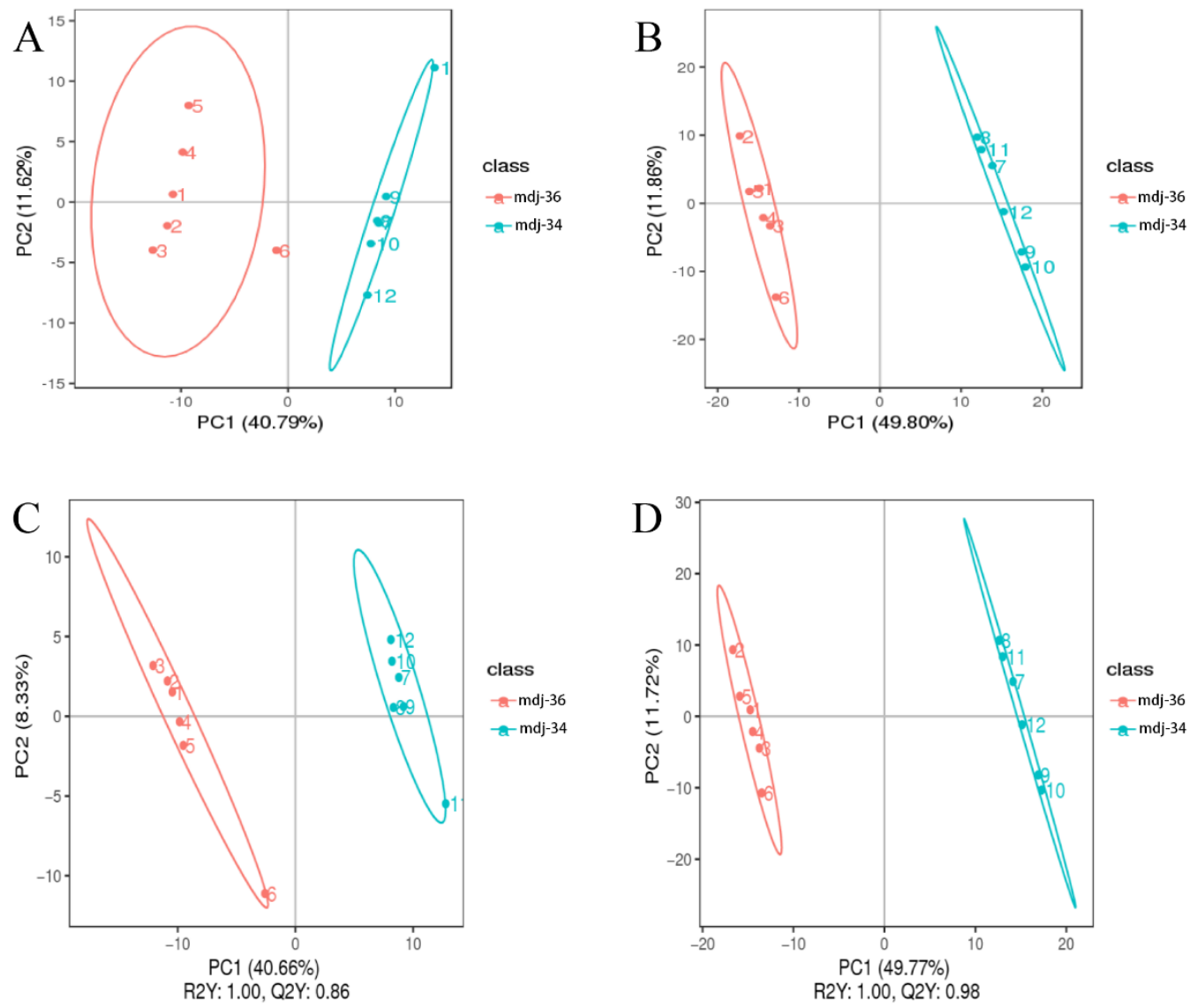

Figure 3. Principal components analysis (PCA) and partial least squares discriminant analysis (PLS-DA) of the metabolism differences between $B$. velezensis mdj-36 and mdj-34 growth media based on Liquid Chromatography Mass Spectrometry (LC-MS). (A) PCA analysis in the positive mode; (B) PCA analysis in the negative mode; (C) PLS-DA analysis in the positive mode; and (D) PLS-DA analysis in the negative mode. 


\subsection{Differentially Expressed Metabolites (DEMs) Analysis}

We identified 489 DEMs in the B. velezensis mdj_36 and B. velezensis mdj_34 growth media. Among these, 166 DEMs had significant variations and so were monitored closely. We identified 103 up-regulated metabolites and 63 down-regulated metabolites between the B. velezensis mdj_36 and mdj_34 growth media (Figure 4).

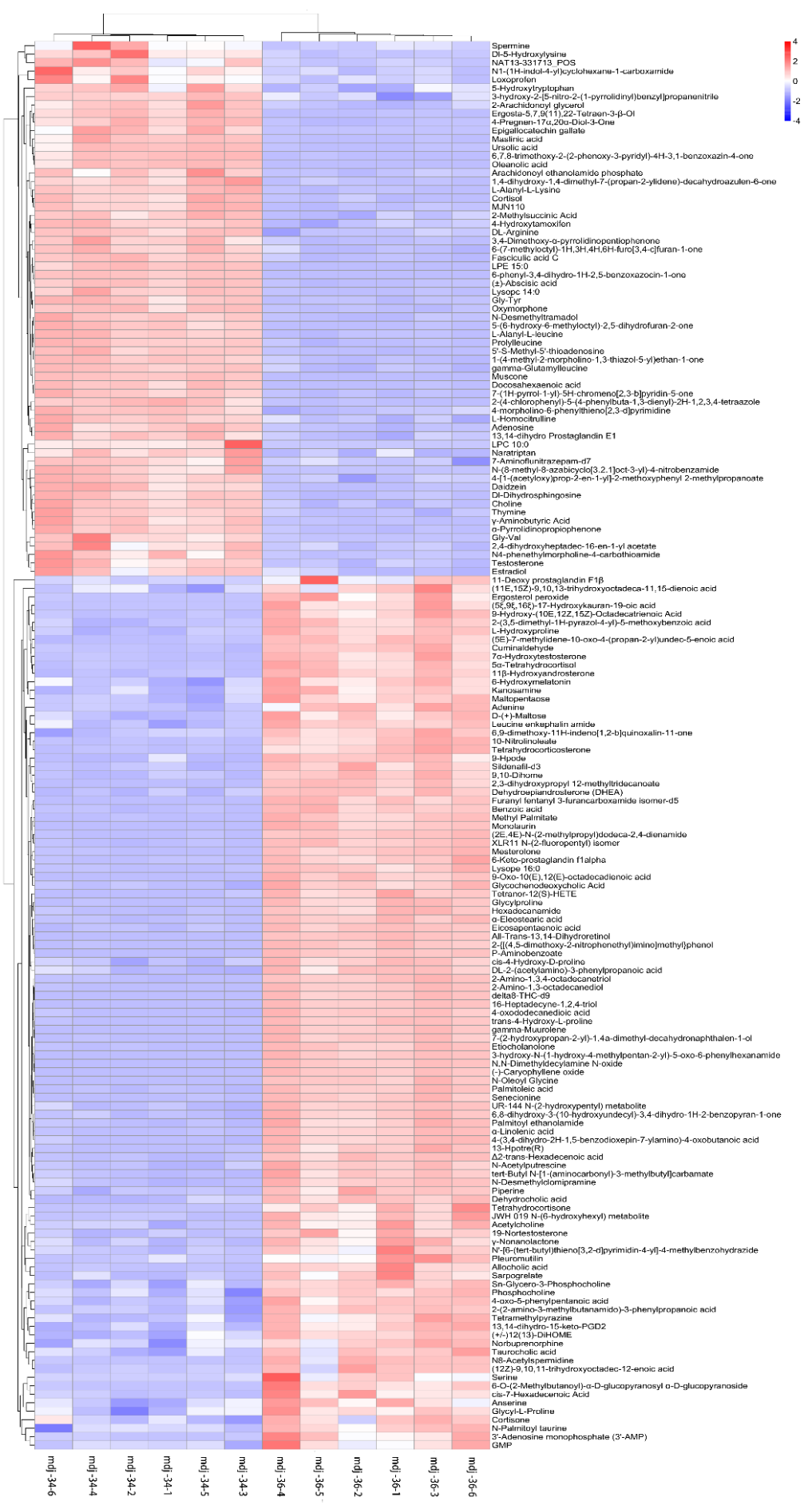

Figure 4. Heatmap analysis of the differentially expressed metabolites (DEMs) in the B. velezensis mdj-36 and mdj-34 growth media. The tree indicates the similarity of metabolites, and the color corresponds to the amount of each metabolite. Each column represents one sample. 
We used the Z-score method to assess the different metabolites of the B. velezensis mdj_36 and mdj_34 growth media based on LC-MS/MS analysis. The top 30 DEMs identified by $p$-value are reported (Figure 5). Substantial changes were observed in the following compounds-amino acids, organic acids, diterpenes $(5 \varepsilon, 9 \varepsilon, 16 \varepsilon)$-17-Hydroxykauran-19oic acid), sesquiterpene hydrocarbon ( $\gamma$-muurolene), ketone (mesterolone and muscone), and glycol (2-Amino-1,3,4-octadecanetriol, 2-Amino-1,3-octadecanediol, 16-Heptadecyne1,2,4-triol). Notably, three amino acids (trans-4-Hydroxy-L-proline, N-Oleoyl Glycine, and L-Alanyl-L-leucine) were found in significantly high proportions in the B. velezensis mdj_36 growth media. In this media, we identified six organic acids with remarkably high levels: $\gamma$-aminobutyric acid, $\alpha$-linolenic acid, $\alpha$-eleostearic acid, benzoic acid, docosahexaenoic acid, and 9-Oxo-10(E),12(E)-octadecadienoic acid.

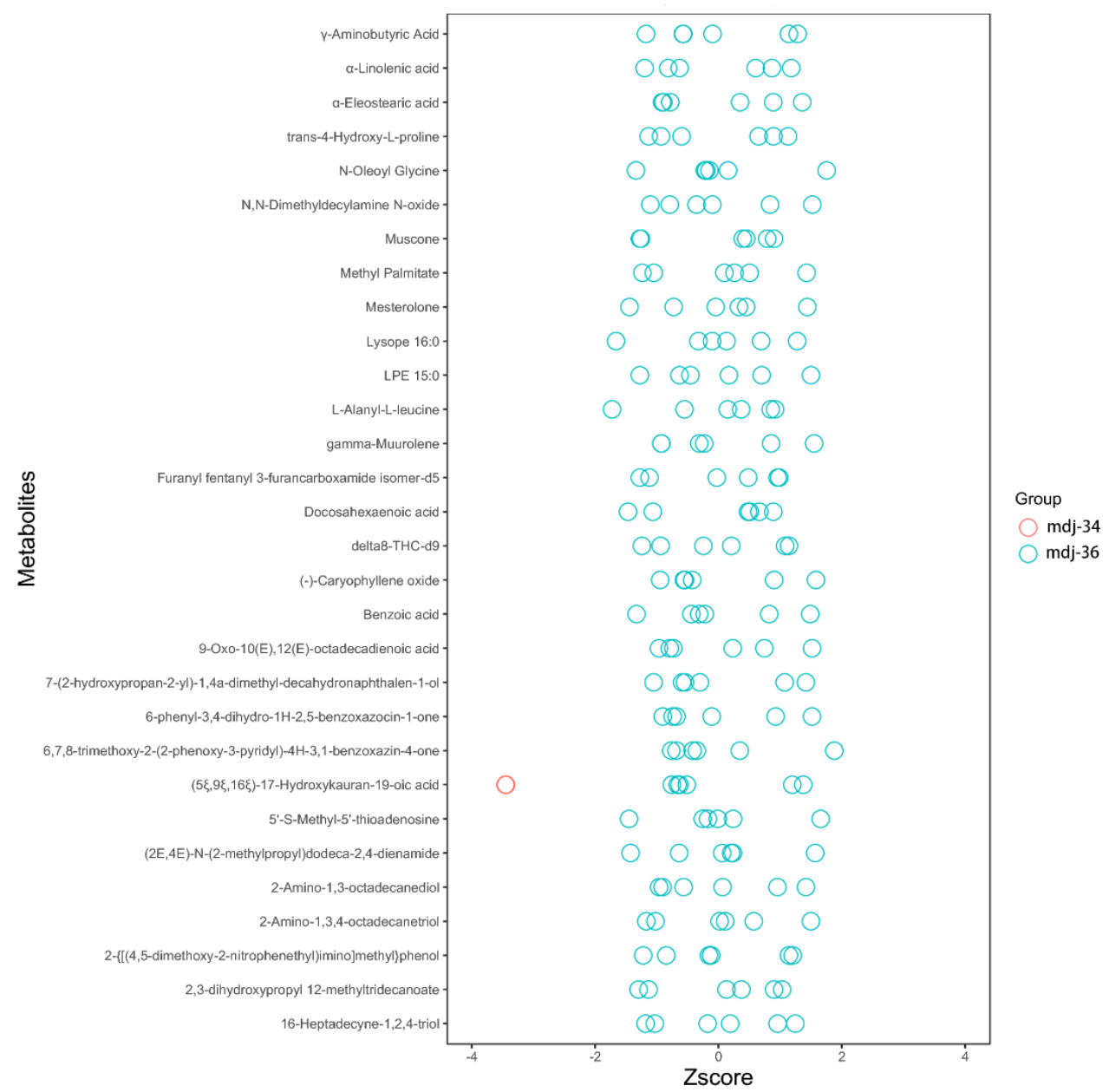

Figure 5. A plot comparing significantly different metabolites in the B. velezensis mdj_36 and mdj-34 growth media based on LC-MS/MS. The horizontal axis is Z-score, the vertical axis designates significantly-altered metabolites. The figure only shows the Top 30 significantly changed metabolites based on the Z-score value.

\subsection{Biological Pathway Enrichment Analysis}

DEMs were further studied using the KEGG enrichment analysis protocol. As shown in Figure 6, the 20 most enriched pathways include 'secondary bile acid biosynthesis', 'glycerophospholipid metabolism', 'biosynthesis of unsaturated fatty acids', 'arginine and proline metabolism', 'fatty acid biosynthesis', 'benzoate degradation', 'taurine and hypotaurine metabolism', 'sphingolipid metabolism', 'xylene degradation', 'glyoxylate and dicarboxylate metabolism', 'sulfur metabolism', 'carbon metabolism', 'bacterial chemotaxis', 'purine metabolism', 'glycine, serine and threonine metabolism', 'beta-Alanine metabolism', 'biosynthesis of antibiotics', 'degradation of aromatic compounds', and 'Vancomycin re- 
sistance'. Furthermore, the 'secondary bile acid biosynthesis' and 'glycerophospholipid metabolism' were the most significant enrichment pathways.

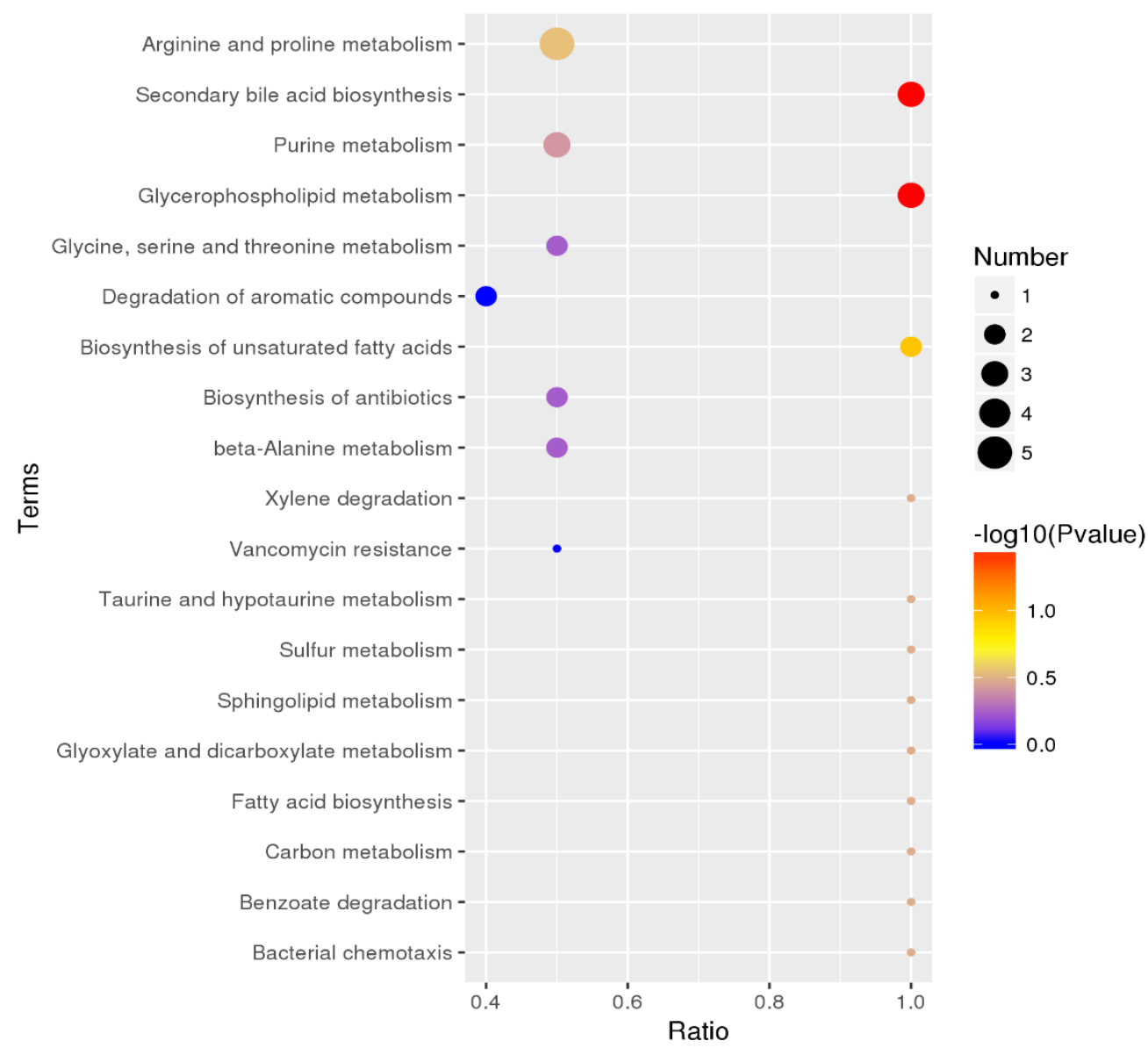

Figure 6. Bubble plot of Kyoto Encyclopedia of Genes and Genomes (KEGG) pathway enrichment for DEMs comparing B. velezensis mdj_36 and mdj-34 growth media. The rich factor is the ratio of the DEM number to the background number in an individual pathway. The rich factor value and degree of pathway enrichment are directly proportional. The dots' size represents the number of proteins, and the color of the dots represents the range of $-\log 10 p$-value, and a lower $-\log 10 p$-value indicates more significant pathway enrichment.

\section{Discussion}

Seedling blight is caused by the fungus F. oxysporum through infection of healthy seedlings by the systemic spreading of spores or mycelia [21]. As a mitigation strategy, biocontrol techniques have been proposed because they are environment-friendly and contribute towards a more sustainable agricultural system globally. The primary objective of plant disease biocontrol is to utilize one or more living organisms with antagonistic effects against a plant pathogen to achieve plant disease suppression. Microbes are isolated as a first step, and pure cultures' inhibitory effects are assessed [22]. In the present study, out of the ten bacterial strains that were isolated from the rice tissues, mdj-36 showed the strongest in vitro pathogen inhibition of $F$. oxysporum, while mdj-34 displayed the lowest antagonistic activity. Both were identified as B. velezensis strains based on the $16 \mathrm{~S}$ rRNA gene sequences. Several reports have described Bacillus strains as promising biocontrol agents for plant diseases [23]. Accumulated evidence has also shown that B. subtilis, $B$. amyloliquifaciens, and B. pumilis had biocontrol efficiency [21,24-26]. Recently, it has been reported that $B$. velezensis B006 could produce surfactin to control suppressing cucumber and pepper root rot diseases caused by F. oxysporum and Phytophthora capsica [20]. Cui et al. have isolated an endophytic bacteria B. velezensis 8-4, which exhibited biocontrol 
activity against Streptomyces galilaeus on potato and displayed inhibitory effects against four other potato pathogens, named F. avenaceum, R. solani Phoma foveat, and Colletotrichum coccodes [17]. Abdelkhalek et al. have reported that B. velezensis PEA1 could inhibit $F$. oxysporum growth and induces systemic resistance to cucumber mosaic virus [27].

Metabolomics techniques have promising future applications in sustainable agriculture as they provide an effective platform for the chemical screening, comparison, and validation of the metabolites from bacterial fermentation [28]. To mine the metabolite signature of endophytic bacteria showing defense response towards F. oxysporum, we used the metabolomics approach based on LC-MS to compare the B. velezensis mdj-36 and mdj-34 growth media. The current study identified significantly high levels of six organic acids in B. velezensis mdj_36 growth media, including $\gamma$ - aminobutyric acid. An earlier study demonstrated that $\gamma$-aminobutyric acid had strong antifungal effects in harvested fruits [29]. Also, phenolic acids have been effective against major fungal pathogens like Candida albicans strains, which are also infectious to humans [30]. The growth inhibition of F. oxysporum by benzoic acid has been reported previously [31].

This study also explored the mechanistic molecular roles of fatty acids in seedling blight inhibition. Although fatty acids are known to possess several antimicrobial properties, increased incidences of acquired microbial resistances that reduce the efficacy of conventional antimicrobial therapies have intensified research activities searching for alternative agents. Also, fatty acids are more environment-friendly compared to chemical fungicides [32]. Previous studies have reported the potential fungicidal properties of some fatty acids [33]. In our research, the fatty acid investigated was $\alpha$-Linolenic acid. Our findings agree with a recent report by Munir et al., who reported that endophyte $B$. subtilis L1-21 in citrus could up-regulate $\alpha$-Linolenic acid to protect citrus against Candidatus Liberibacter asiaticus [34]. Moreover, the concentration of $\alpha$-eleostearic acid derived from $\alpha$-linolenic acid was also higher in B. velezensis mdj_36 growth media than $B$. velezensis mdj_34 [35]. Surup et al. reported that $\alpha$-eleostearic acid isolated from cultures of the tropical Ascomycete Hypoxylon rickii showed antimicrobial and cytotoxic activities [36].

Our metabolomics results reveal that the levels of some polyunsaturated fatty acids (FUFAs) were substantially elevated in the B. velezensis mdj_36 growth media. Interestingly, these include docosahexaenoic acid (DHA) and 9-oxo-10(E),12(E)-octadecadienoic acid (9-oxoODA). An earlier study by Bajpal et al. showed that DHA significantly inhibited spore formation in seven economic plant pathogens in an initial screening protocol, and this was validated in an in vivo screening [37]. Similarly, Bilikova et al. demonstrated that 9-oxo-10(E)-12(Z)-octadecadienoic acid inhibited the pathogenic activities of Paenibacillus larvae [38]. Also, the results of a dose-dependent study by Cantrell et al. showed that some Gomphus floccosus-derived fatty acids suppressed the activities of several fungal plant pathogens, including F. oxysporum and B. cinerea [39]. Thus, our observations support existing evidence that these bioactive organic compounds can have future applications in raising major crops' resistance against notable economic pathogens.

Some suppressive properties have also been observed with the kaurene diterpene $(5 \varepsilon, 9 \varepsilon, 16 \varepsilon)-17-H y d r o x y k a u r a n-19-o i c ~ a c i d$, a diterpene containing a rigid tetracyclic skeleton known as kaurenoic acid [40]. In combination with similar compounds, a significant increase in inhibitory activities has been reported [41]. Sequel to these, Helliwell et al. and Nozaki et al. confirm that kaurene compounds, being intermediates in plant and fungal metabolites' biosynthesis, have a range of bactericidal and fungicidal activities [42,43]. A previous study also found that five diterpenes with the kaurane skeleton (ent-kaur-16-en19-oic acid, ent-19-methoxy-19-oxokauran-17-oic acid, annoglabasin B, ent-17-hydroxykaur15-en-19-oic acid, and ent-15b,16b-epoxy-17-hydroxy-kauran-19-oic acid) were isolated from $A$. glabra leaves has also shown antifungal effects [44,45]. Earlier, a GC-MS study by Cheng et al. revealed that the essential oils from Japanese cedar heartwood contained $\delta$-cadinene, isoledene, and $\gamma$-muurolene, conferring it with many fungicidal properties [46]. Recently, some major and minor terpenes exhibited antifungal properties against several plant pathogens, including B. cinerea, C. gloeosporioides, and P. cinnamomic [47], reiterat- 
ing the current study's position that naturally-occurring compounds should be further explored in mitigating the activities of plant fungal pathogens.

Among the pathways explored in our study, 'secondary bile acid biosynthesis' and 'glycerophospholipid metabolism,' which have the lowest-log10 $p$-value compared with other routes, is the most significant enrichment pathway. Consistent with our results, Guinan et al. recently opined that the notable fungal pathogen's activities, Candida albicans, could be inhibited by secondary bile acids [48]. Also, bile acids stimulate a more significant defense pathway than a fungal cerebroside obtained from the rice pathogen, Magnaporthe grisea [49]. As an integral cell membrane structure, the glycerophospholipid bilayer performs a dual role in protecting cell components from the external environment and ensuring uninterrupted internal cell biological functions [50]. These findings revealed that $B$. velezensis mdj_36 could play a better role against $F$. oxysporum than $B$. velezensis mdj_34 through enhanced cell structure and biosynthesis of essential proteins.

\section{Conclusions}

Seedling blight is a significant limitation to global rice production. In this study, an endophytic bacteria $B$. velezensis strain mdj-36 was isolated from rice samples. It exhibited a high inhibitory ability against $F$. oxysporum, known as the causal agent of seedling blight. The metabolomics results revealed that $B$. velezensis mdj-36 could produce higher levels of organic acids, terpenes, and diterpene than that in B. velezensis mdj-34, which is sensitive to F. oxysporum. Further analysis highlighted the vital role of 'secondary bile acid biosynthesis' and 'glycerophospholipid metabolism' pathways. In all, our study has provided additional information regarding the molecular mechanisms underlying of $B$. velezensis strain as a biocontrol agent against rice seedling blight. It can be a sound theoretical basis for further studies of this microbe as a disease-suppressing agent.

Author Contributions: Conceptualization, W.D. and Y.C.; methodology, Y.C.; software, C.L.; formal analysis, C.L.; investigation, Y.C.; resources, W.D; data curation, Y.C.; writing-original draft preparation, Y.C.; writing - review and editing, W.D.; visualization, C.L.; supervision, W.D.; project administration, W.D.; funding acquisition, W.D. All authors have read and agreed to the published version of the manuscript.

Funding: This research was funded by Science and Technology Project of Heilongjiang Province, grant number GC12B103 and Harbin Excellent Academic Leader Project, grant number 2016RAXXJ033. The APC was funded by Science and Technology Project of Heilongjiang Province.

Conflicts of Interest: The authors declare no conflict of interest.

\section{References}

1. Mir, S.; Bhat, M.A.; Bashir, A.; Rashid, R.; Bano, H.; Mir, S.A. Present Status and Future Prospects of Marker Assisted Selection for Sheath Blight Resistance Breeding in Rice (Oryza sativa L.). Skuast J. Res. 2015, 17, 72-90.

2. Ma, B.; Wang, J.; Liu, C.; Hu, J.; Tan, K.; Zhao, F.; Yuan, M.; Zhang, J.; Gai, Z. Preventive Effects of Fluoro-Substituted Benzothiadiazole Derivatives and Chitosan Oligosaccharide against the Rice Seedling Blight Induced by Fusarium oxysporum. Plants 2019, 8, 538. [CrossRef] [PubMed]

3. Shaheen, R.; Sharif, M.Z.; Amrao, L.; Zheng, A.; Manzoor, M.; Majeed, D.; Kiran, H.; Jafir, M.; Ali, A. Investigation of bacterial leaf blight of rice through various detection tools and its impact on crop yield in Punjab, Pakistan. Pak. J. Bot. 2019, 51, 307-312. [CrossRef]

4. Nasir, M.; Iqbal, B.; Hussain, M.; Mustafa, A.; Ayub, M. Chemical management of bacterial leaf blight disease in rice. J. Agric. Res. 2019, 57, 93-98.

5. Singh, U.B.; Malviya, D.; Singh, S.; Pradhan, J.K.; Singh, B.P.; Roy, M.; Imram, M.; Pathak, N.; Baisyal, B.; Rai, J.P. Bio-protective microbial agents from rhizosphere eco-systems trigger plant defense responses provide protection against sheath blight disease in rice (Oryza sativa L.). Microbiol. Res. 2016, 192, 300-312. [CrossRef]

6. Guan, S.-h.; Sattler, I.; Lin, W.-h.; Guo, D.-a.; Grabley, S. p-Aminoacetophenonic Acids Produced by a Mangrove Endophyte: Streptomyces g riseus subsp. J. Nat. Prod. 2005, 68, 1198-1200. [CrossRef] [PubMed]

7. Senthilkumar, M.; Govindasamy, V.; Annapurna, K. Role of antibiosis in suppression of charcoal rot disease by soybean endophyte Paenibacillus sp. HKA-15. Curr. Microbiol. 2007, 55, 25-29. [CrossRef]

8. Brader, G.; Compant, S.; Mitter, B.; Trognitz, F.; Sessitsch, A. Metabolic potential of endophytic bacteria. Curr. Opin. Biotechnol. 2014, 27, 30-37. [CrossRef] [PubMed] 
9. Radhakrishnan, R.; Hashem, A.; Abd_Allah, E.F. Bacillus: A biological tool for crop improvement through bio-molecular changes in adverse environments. Front. Physiol. 2017, 8, 667. [CrossRef] [PubMed]

10. Lilley, A.K.; Fry, J.C.; Bailey, M.J.; Day, M.J. Comparison of aerobic heterotrophic taxa isolated from four root domains of mature sugar beet (Beta vulgaris). Fems Microbiol. Ecol. 1996, 21, 231-242. [CrossRef]

11. Mahaffee, W.; Kloepper, J. Temporal changes in the bacterial communities of soil, rhizosphere, and endorhiza associated with field-grown cucumber (Cucumis sativus L.). Microb. Ecol. 1997, 34, 210-223. [CrossRef]

12. Nagendran, K.; Karthikeyan, G.; Peeran, M.F.; Raveendran, M.; Prabakar, K.; Raguchander, T. Management of bacterial leaf blight disease in rice with endophytic bacteria. World Appl Sci J 2013, 28, 2229-2241.

13. Nagendran, K.; Karthikeyan, G.; Mohammed Faisal, P.; Kalaiselvi, P.; Raveendran, M.; Prabakar, K.; Raguchander, T. Exploiting endophytic bacteria for the management of sheath blight disease in rice. Biol. Agric. Hortic. 2014, 30, 8-23. [CrossRef]

14. El-Shafey, R.A.; Attia, K.A.; Mostafa, F.A.; Elamawi, R.M. Incidence and molecular identification of Cochliobolus carbonum as causal organism of rice seedling blight. Beni-Suef Univ. J. Basic Appl. Sci. 2018, 7, 652-662. [CrossRef]

15. Suhandono, S.; Kusumawardhani, M.K.; Aditiawati, P. Isolation and molecular identification of endophytic bacteria from Rambutan fruits (Nephelium lappaceum L.) cultivar Binjai. Hayati J. Biosci. 2016, 23, 39-44. [CrossRef]

16. Gajbhiye, A.; Rai, A.R.; Meshram, S.U.; Dongre, A. Isolation, evaluation and characterization of Bacillus subtilis from cotton rhizospheric soil with biocontrol activity against Fusarium oxysporum. World J. Microbiol. Biotechnol. 2010, 26, 1187-1194. [CrossRef]

17. Cui, L.; Yang, C.; Wei, L.; Li, T.; Chen, X. Isolation and identification of an endophytic bacteria Bacillus velezensis 8-4 exhibiting biocontrol activity against potato scab. Biol. Control 2020, 141, 104156. [CrossRef]

18. Want, E.J.; O'Maille, G.; Smith, C.A.; Brandon, T.R.; Uritboonthai, W.; Qin, C.; Trauger, S.A.; Siuzdak, G. Solvent-dependent metabolite distribution, clustering, and protein extraction for serum profiling with mass spectrometry. Anal. Chem. 2006, 78, 743-752. [CrossRef] [PubMed]

19. Wu, Q.; Ni, M.; Dou, K.; Tang, J.; Ren, J.; Yu, C.; Chen, J. Co-culture of Bacillus amyloliquefaciens ACCC11060 and Trichoderma asperellum GDFS1009 enhanced pathogen-inhibition and amino acid yield. Microb. Cell Fact. 2018, 17, 1-12. [CrossRef] [PubMed]

20. Wang, J.; Guo, R.; Wang, W.; Ma, G.; Li, S. Insight into the surfactin production of Bacillus velezensis B006 through metabolomics analysis. J. Ind. Microbiol. Biotechnol. 2018, 45, 1033-1044. [CrossRef] [PubMed]

21. Zhao, P.; Quan, C.; Wang, Y.; Wang, J.; Fan, S. Bacillus amyloliquefaciens Q-426 as a potential biocontrol agent against Fusarium oxysporum f. sp. spinaciae. J. Basic Microbiol. 2014, 54, 448-456. [CrossRef] [PubMed]

22. Pal, K.K.; Gardener, B.M. Biological control of plant pathogens. Plant Health Instr. 2006, 2, 1117-1142. [CrossRef]

23. Shoda, M. Bacterial control of plant diseases. J. Biosci. Bioeng. 2000, 89, 515-521. [CrossRef]

24. Yang, L.; Quan, X.; Xue, B.; Goodwin, P.H.; Lu, S.; Wang, J.; Du, W.; Wu, C. Isolation and identification of Bacillus subtilis strain YB-05 and its antifungal substances showing antagonism against Gaeumannomyces graminis var. tritici. Biol. Control 2015, 85, 52-58. [CrossRef]

25. Siddiqui, S.; Siddiqui, Z.A.; Ahmad, I. Evaluation of fluorescent Pseudomonads and Bacillus isolates for the biocontrol of a wilt disease complex of pigeonpea. World J. Microbiol. Biotechnol. 2005, 21, 729-732. [CrossRef]

26. Elanchezhiyan, K.; Keerthana, U.; Nagendran, K.; Prabhukarthikeyan, S.R.; Prabakar, K.; Raguchander, T.; Karthikeyan, G. Multifaceted benefits of Bacillus amyloliquefaciens strain FBZ24 in the management of wilt disease in tomato caused by Fusarium oxysporum f. sp. lycopersici. Physiol. Mol. Plant Pathol. 2018, 103, 92-101. [CrossRef]

27. Abdelkhalek, A.; Behiry, S.I.; Al-Askar, A.A. Bacillus velezensis PEA1 inhibits Fusarium oxysporum growth and induces systemic resistance to cucumber mosaic virus. Agronomy 2020, 10, 1312. [CrossRef]

28. Wu, C.; Kim, H.K.; van Wezel, G.P.; Choi, Y.H. Metabolomics in the natural products field-A gateway to novel antibiotics. Drug Discov. Today Technol. 2015, 13, 11-17. [CrossRef]

29. Yu, C.; Zeng, L.; Sheng, K.; Chen, F.; Zhou, T.; Zheng, X.; Yu, T. $\gamma$-Aminobutyric acid induces resistance against Penicillium expansum by priming of defence responses in pear fruit. Food Chem. 2014, 159, 29-37. [CrossRef]

30. Zabka, M.; Pavela, R. Antifungal efficacy of some natural phenolic compounds against significant pathogenic and toxinogenic filamentous fungi. Chemosphere 2013, 93, 1051-1056. [CrossRef]

31. Wu, H.-S.; Wang, Y.; Zhang, C.-Y.; Gu, M.; Liu, Y.-X.; Chen, G.; Wang, J.-H.; Tang, Z.; Mao, Z.-S.; Shen, Q.-R. Physiological and biochemical responses of in vitro Fusarium oxysporum f. sp. niveum to benzoic acid. Folia Microbiol. 2009, 54, 115-122. [CrossRef]

32. Pohl, C.H.; Kock, J.L.; Thibane, V.S. Antifungal free fatty acids: A review. Sci. Against Microb. Pathog. Commun. Curr. Res. Technol. Adv. 2011, 3, 61-71.

33. Kabara, J.J.; Swieczkowski, D.M.; Conley, A.J.; Truant, J.P. Fatty acids and derivatives as antimicrobial agents. Antimicrob. Agents Chemother. 1972, 2, 23-28. [CrossRef]

34. Munir, S.; Li, Y.; He, P.; He, P.; Ahmed, A.; Wu, Y.; He, Y. Unraveling the metabolite signature of citrus showing defense response towards Candidatus Liberibacter asiaticus after application of endophyte Bacillus subtilis L1-21. Microbiol. Res. 2020, $234,126425$. [CrossRef] [PubMed]

35. Killiny, N.; Nehela, Y. Metabolomic response to Huanglongbing: Role of carboxylic compounds in Citrus sinensis response to 'Candidatus Liberibacter asiaticus' and its vector, Diaphorina citri. Mol. Plant Microbe Interact. 2017, 30, 666-678. [CrossRef]

36. Surup, F.; Kuhnert, E.; Liscinskij, E.; Stadler, M. Silphiperfolene-type terpenoids and other metabolites from cultures of the tropical ascomycete Hypoxylon rickii (Xylariaceae). Nat. Prod. Bioprospect. 2015, 5, 167-173. [CrossRef] 
37. Bajpai, V.K.; Kim, H.R.; Hou, C.T.; Kang, S.C. Microbial conversion and in vitro and in vivo antifungal assessment of bioconverted docosahexaenoic acid (bDHA) used against agricultural plant pathogenic fungi. J. Ind. Microbiol. Biotechnol. 2009, $36,695$. [CrossRef] [PubMed]

38. Bilikova, K.; Popova, M.; Trusheva, B.; Bankova, V. New anti-Paenibacillus larvae substances purified from propolis. Apidologie 2013, 44, 278-285. [CrossRef]

39. Cantrell, C.; Case, B.; Mena, E.; Kniffin, T.; Duke, S.; Wedge, D. Isolation and identification of antifungal fatty acids from the basidiomycete Gomphus floccosus. J. Agric. Food. Chem. 2008, 56, 5062-5068. [CrossRef]

40. Seaman, F.; Bohlmann, F.; Zdero, C.; Mabry, T.J. Diterpenes of Flowering Plants: COMPOSITAE (Asteraceae); Springer: Berlin/Heidelberg, Germany, 2012.

41. Ghisalberti, E. The biological activity of naturally occurring kaurane diterpenes. Fitoterapia 1997, 68, 303-325.

42. Helliwell, C.A.; Chandler, P.M.; Poole, A.; Dennis, E.S.; Peacock, W.J. The CYP88A cytochrome P450, ent-kaurenoic acid oxidase, catalyzes three steps of the gibberellin biosynthesis pathway. Proc. Natl. Acad. Sci. USA 2001, 98, 2065-2070. [CrossRef] [PubMed]

43. Nozaki, H.; Hayashi, K.-i.; Okuda, K.; Kuyama, F.; Ono, K.; Matsuo, A. ent-Kaurane-type diterpenoids from a cell suspension culture of the liverwort Jungermannia subulata. Planta Med. 2007, 73, 689-695. [CrossRef] [PubMed]

44. Matsumoto, S.; Varela, R.M.; Palma, M.; Molinillo, J.M.; Lima, I.S.; Barroso, C.G.; Macías, F.A. Bio-guided optimization of the ultrasound-assisted extraction of compounds from Annona glabra L. leaves using the etiolated wheat coleoptile bioassay. Ultrason. Sonochem. 2014, 21, 1578-1584. [CrossRef]

45. Rocha, G.S.; Matsumoto, R.S.; Lombardi, A.T.; Lima, M.I.S. Potential effects of fungicide and algaecide extracts of Annona glabra L.(Annonaceae) on the microalgae Raphidocelis subcapitata and on the oomycete Pythium. An. Acad. Bras. Cienc. 2017, 89, 2101-2111. [CrossRef]

46. Cheng, S.-S.; Lin, H.-Y.; Chang, S.-T. Chemical composition and antifungal activity of essential oils from different tissues of Japanese cedar (Cryptomeria japonica). J. Agric. Food. Chem. 2005, 53, 614-619. [CrossRef]

47. Yan, D.-H.; Song, X.; Li, H.; Luo, T.; Dou, G.; Strobel, G. Antifungal activities of volatile secondary metabolites of four Diaporthe strains isolated from Catharanthus roseus. J. Fungi 2018, 4, 65. [CrossRef] [PubMed]

48. Guinan, J.; Villa, P.; Thangamani, S. Secondary bile acids inhibit Candida albicans growth and morphogenesis. Pathog. Dis. 2018, 76, fty038. [CrossRef] [PubMed]

49. Koga, J.; Kubota, H.; Gomi, S.; Umemura, K.; Ohnishi, M.; Kono, T. Cholic acid, a bile acid elicitor of hypersensitive cell death, pathogenesis-related protein synthesis, and phytoalexin accumulation in rice. Plant Physiol. 2006, 140, 1475-1483. [CrossRef] [PubMed]

50. Jiao, P.; Cuiting, H.; Jae-Hyuk, Y. Lipid Biosynthesis as an Antifungal Target. J. Fungi 2018, 4, 50. 